\begin{tabular}{c} 
JCEBT, 5 (1) Maret 2021 ISSN 2549-6379 (Print) ISSN 2549-6387 (Online) \\
JCEBT \\
ONournal of Civil Engineering, Building and Transportation) \\
Available online http://ojs.uma.ac.id/index.php/jcebt \\
\hline
\end{tabular}

\title{
PENGARUH SERAT BENDRAT TERHADAP KUAT TEKAN PAVING BLOCK BERBAHAN DASAR LIMBAH PLASTIK HDPE
}

\section{THE EFFECT OF LENDER FIBER ON THE PRESSURE OF PAVING BLOCK BASED ON HDPE WASTE PLASTIC}

\author{
Denny Meisandy Hutauruk \\ Program Studi Teknik Sipil, Fakultas Teknik \\ Universitas Negeri Medan, Indonesia
}

Email: denny_ft@unimed.ac.id

\begin{abstract}
Abstrak
Saat ini, permasalahan sampah semakin mengkhawatirkan, bahkan hingga dalam skala global. Di Indonesia, tercatat peningkatan timbunan sampah hingga 64 juta ton/tahun pada tahun 2015. Penelitian ini akan dilakukan pembuatan pembuatan paving block berbahan dasar limbah pastik HDPE yang dikombinasikan serat kawat dengan variasi persentase 0\%, 1\%, 2\%, 3\% dari volume paving block. Limbah plastik dilelehkan, dimasukkan ke dalam cetakan lalu dicampur dengan serat bendrat dengan 2 tahapan. Dari hasil pengujian, didapatkan kuat tekan tertinggi (kadar serat bendrat 3\%) sebesar 110,7 $\mathrm{kg} / \mathrm{cm} 2$. Kuat tekan ini memenuhi standar kuat tekan paving block mutu D, yang diperuntukkan sebagai perkerasan yang tidak memikul beban besar, seperti pada halaman rumah.

Kata Kunci: paving block, limbah plastik, HDPE (High Density Polyethylene), serat kawat, kuat tekan.
\end{abstract}

\begin{abstract}
Currently, the waste problem is increasingly worrying, even on a global scale. In Indonesia, there is an increase in waste piles up to 64 million tons / year in 2015. This research will carry out the manufacture of paving blocks made from HDPE waste that combines wire fibers with varying proportions of 0\%, 1\%, 2\%, $3 \%$ of the volume of paving blocks. The plastic waste is melted, put into the traffic mold with bend fibers in 2 stages. From the test results, obtained the highest compressive strength (3\% bendrat fiber content) of $110.7 \mathrm{~kg} / \mathrm{cm} 2$. This compressive strength meets the compressive strength standard of quality D paving blocks, which is intended as pavement that does not carry large loads, such as on the home page.

Keywords: paving blocks, plastic waste, HDPE (High Density Polyethylene), bendrat fiber, compressive strength.
\end{abstract}

How to Cite: Hutauruk, D.M.H. (2021). Pengaruh Serat Bendrat Terhadap Kuat Tekan Paving Block Berbahan Dasar Limbah Plastic HDPE. JCEBT (Journal of Civil Engineering, Building and Transportation). 5 (1): 9-16 
Hutauruk, D.M.H. (2021). Pengaruh Serat Bendrat Terhadap Kuat Tekan Paving Block Berbahan Dasar Limbah Plastik HDPE

\section{PENDAHULUAN}

Sampah plastik merupakan permasalahan yang begitu kompleks, termasuk di indonesia. Hal ini disebabkan karena penggunaannya yang tidak terlepas dari kegiatan manusia. Pola pengelolaan sampah di Indonesia yaitu 69\% diangkut dan ditimbun di TPA, 10\% dikubur, 7\% dikompos dan didaur ulang, 5\% dibakar dan sebesar 7\% tidak terkelola. Padahal, plastik baru benar-benar bisa terurai 20 hingga 100 tahun.

Plastik hdpe (High Density Polyethylene) merupakan jenis plastik yang memiliki simbol daur ulang dan angka 2 ditengahnya. Selain hdpe, ada lagi beberapa lagi jenis plastik yang lain. Secara umum, plastik terbagi menjadi beberapa jenis, yaitu:

1. PETE (Polyethylene Terephthalate)

2. PVC (Polyvinyl Chloride)

3. HDPE (High-Density Polyethylene)

4. LDPE (Low-Density Polyethylene)

5. PP (Polypropylene)

6. PS (Polystyrene)

7. Jenis lain (BPA, Polycarbonate, dan LEXAN)

Pada pembuatan beton, ada beberapa macam variasi serat yang bisa digunakan (Dwiyono, 2000):

1. Serat asbestos

2. Serat kaca (glass fiber)

3. Serat baja (steel fiber)
4. Serat karbon

5. Serat polypropylene (tali raffia)

6. Serat polyethylene (tali tambang plastik)

7. Serat alami (seperti serat ijuk, serat sabut kelapa dan sejenisnya)

Kawat bendrat atau kawat beton merupakan material yang biasanya digunakan untuk mengikat tulangan baja utama dengan tulangan sengkang pada konstruksi beton bertulang. Karena diameternya yang sangat kecil (paling kecil 0,8 mm), karakteristik material ini cocok digunakan sebagai serat campuran. Pada penelitian fauna adibroto terdapat peningkatan kuat tekan paving block berbahan beton (kerikil pasir dan semen) dengan penambahan serat bendrat dengan kadar tertentu.

Berdasarkan hal tersebut diatas, maka paving blok akan dibuat dengan bahan dasar plastik hdpe sebagai upaya mengurangi limbah plastik yang tidak terpakai dan menggunakan campuran serat kawat bendrat untuk melihat sejauh mana kekuatan paving block dari kombinasi material tersebut.

Beberapa kelebihan paving block dibandingkan perkerasan lain yaitu:

a) Dapat diproduksi secara massal

b) Dapat digunakan langsung tanpa harus menunggu pengerasan seperti beton

c) Pemasangannya relatif mudah 
d) Tidak menyebabkan gangguan bising dan debu saat pemasangan

Syarat mutu paving block berdasarkan SNI-03-0691-1996 yaitu:

1. Permukaan paving block harus rata, tidak retak, bagian sudut dan rusuknya tidak mudah digerus dengan kekuatan jari tangan.

2. Paving block harus memiliki sifat fisika seperti pada Tabel 1 dibawah.

Tabel 1. Kuat Fisik Paving Block

\begin{tabular}{|c|c|c|c|c|c|}
\hline \multirow{2}{*}{$\begin{array}{c}\text { Mut } \\
\mathrm{u}\end{array}$} & \multicolumn{2}{|c|}{$\begin{array}{c}\text { Kuat Tekan } \\
\text { (MPa) }\end{array}$} & \multicolumn{2}{c|}{ Ketahanan Aus } & $\begin{array}{c}\text { Penyerapa } \\
\text { n air rata- } \\
\text { rata maks. }\end{array}$ \\
\cline { 2 - 6 } & $\begin{array}{c}\text { Rerat } \\
\text { a }\end{array}$ & $\begin{array}{c}\text { Minim } \\
\text { al }\end{array}$ & $\begin{array}{c}\text { Rerat } \\
\text { a }\end{array}$ & $\begin{array}{c}\text { Minim } \\
\text { al }\end{array}$ & $\%$ \\
\hline A & 40 & 35 & 0,090 & 0,103 & 3 \\
\hline B & 20 & 17 & 0,130 & 0,149 & 6 \\
\hline C & 15 & 12,5 & 0,160 & 0,184 & 8 \\
\hline D & 10 & 8,5 & 0,219 & 0,251 & 10 \\
\hline
\end{tabular}

Sumber: SNI 03-0691-1996: Bata Beton (Paving Block)

Dapat dilihat pada tabel diatas, paving block dengan mutu A memiliki kuat tekan paling tinggi (minimal $35 \mathrm{MPa}$ dan rerata $40 \mathrm{MPa}$ ). Paving block mutu A biasanya digunakan untuk jalan, lahan terminal truk container dan perkerasan lain yang menahan beban besar. Paving block dengan mutu D hanya memiliki kuat tekan minimal 8,5 $\mathrm{MPa}$ dan rerata $10 \mathrm{MPa}$. Karena kuat tekannya yang rendah, biasanya paving block mutu D digunakan untuk perkerasan non-struktural, misalnya perkerasan taman, halaman rumah, trotoar, dan perkerasan lain yang tidak menahan beban besar.
Gusniar (2018) meneliti paving block berbahan dasar plastik HDPE dan mendapatkan hasil paving block dengan kuat tekan 220,85 $\mathrm{kg} / \mathrm{cm}^{2}$. Nilai ini termasuk paving block mutu $\mathrm{C}$, dimana nilai kuat tekan minimalnya 127,55 $\mathrm{kg} / \mathrm{cm}^{2}$.

Pada penelitian yang dilakukan Adibroto (2014) terhadap pengaruh penambahan serat kawat bendrat pada paving blok konvensional (campuran pasir+semen+kerikil), didapatkan kuat tekan maksimum sebesar $341,52 \mathrm{~kg} / \mathrm{cm}^{2}$ (persentase serat bendrat 3\%). Nilai ini lebih tinggi jika dibandingkan dengan kuat tekan paving block tanpa tambahan serat (persentase serat bendrat 0\%) yaitu sebesar $327,38 \mathrm{~kg} / \mathrm{cm}^{2}$.

Sari dan nusa (2019) melakukan penelitian terkait pengaruh limbah plastik hdpe sebagai bahan dasar paving block terhadap kuat tekannya. Didapatkan hasil bahwa kuat tekan paving block berbahan dasar plastik memiliki kuat tekan 50\% lebih kecil dibandingkan paving block konvensional (campuran pasir+semen).

\section{METODE PENELITIAN}

\section{Persiapan Material}

Secara garis besar, tahapan penelitian bisa dilihat pada Gambar 1. Plastik yang digunakan ialah plastik botol berjenis HDPE dengan ciri adanya simbol daur 
ulang dan angka 2 ditengahnya pada dasar botol. Botol plastik ini dikumpulkan dari Gudang Botot di jalan sunggal, Medan. Setelah dikumpulkan, plastik dicuci bersih agar tidak ada kotoran yang menempel.

Serat bendrat yang digunakan pada penelitian ini ialah kawat bendrat yang berdiameter $0,8 \mathrm{~mm}$ yang biasa digunakan sebagai pengikat rangkaian tulangan pada beton bertulang. Berdasarkan panjang, kawat bendrat ini dipotong menjadi $3 \mathrm{~cm}$. berdasarkan rasio volume serat terhadap volume paving block, kawat bendrat ini dibuat menjadi 3 varian, yaitu 1\%, 2\%, dan $3 \%$, dimana setiap varian dibuat menjadi 5 sampel.

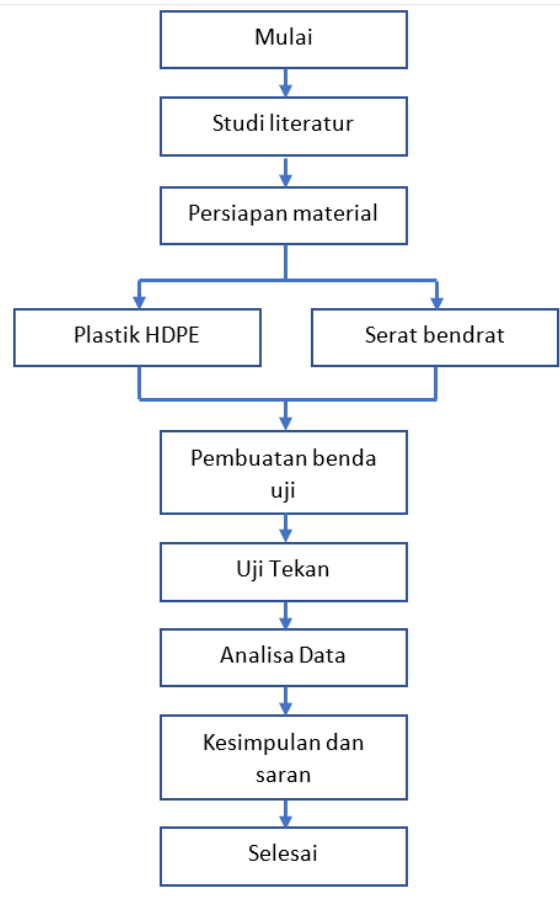

Gambar 1. Flow Chart Penelitian

\section{Pembuatan Benda Uji}

Setelah botol plastik telah kering, selanjutnya dilelehkan dengan menggunakan kuali. Untuk mempercepat proses pelelehan, botol dibakar terlebih dahulu dari atas kuali. Proses pembakaran dilakukan \pm 30 menit. Olesi cetakan terlebih dahulu sebelum melakukan penuangan, agar sampel tidak lengket. Pada saat penuangan, serat kawan bendrat disebar dengan 2 tahap, yaitu pada $2 \mathrm{~cm}$ pertama penuangan, dan $4 \mathrm{~cm}$ terakhir. Penyebaran serat bendrat dilakukan secara acak dan dengan cepat agar tidak mengeras sebelum penuangan selesai. Setelah sampel telah penuh, selanjutnya diberikan tekanan. setelah sampel dibiarkan selama \pm 1 jam, sampel dikeluarkan dari cetakan.

\section{Pengujian Kuat Tekan}

Sampel diuji 24 jam setelah dikeluarkan dari cetakan, lalu diuji dengan menggunakan compression testing machine dengan tahapan sebagai berikut:

a. Meletakkan sampel pada landasan

b. Mengatur jarum hingga menyentuh angka nol

c. Melakukan penekanan

d. Mencatat nilai maksimum beban yang ditahan oleh sampel hingga mengalami runtuh/patah.

Kuat tekan $=\mathrm{P} / \mathrm{L}$ 
Dimana:

$\mathrm{P}=$ beban maksimum $(\mathrm{kg})$

$\mathrm{L}=$ luas bidang tekan.

\section{HASIL DAN PEMBAHASAN}

\section{Kuat Tekan Paving Block Kadar Serat}

\section{Bendrat 0\%}

Tabel 2 merupakan hasil uji kuat tekan paving block tanpa menggunakan serat bendrat. Dapat dilihat bahwa kuat tekan yang dihasilkan sangat kecil dan tidak sesuai dengan standar SNI.

Tabel 2. Hasil Uji Kuat Tekan Paving Blok Berbahan Dasar Limbah Plastik Hdpe Dengan Kadar Serat 0\%

\begin{tabular}{|c|c|c|}
\hline No & Kadar Serat 0\% & Kuat Tekan $\left(\mathrm{kg} / \mathrm{cm}^{2}\right)$ \\
\hline 1 & Sampel 1 & 42,63 \\
\hline 2 & Sampel 2 & 43,18 \\
\hline 3 & Sampel 3 & 45,11 \\
\hline 4 & Sampel 4 & 43,63 \\
\hline 5 & Sampel 5 & 44,55 \\
\hline
\end{tabular}

Sumber: Analisa

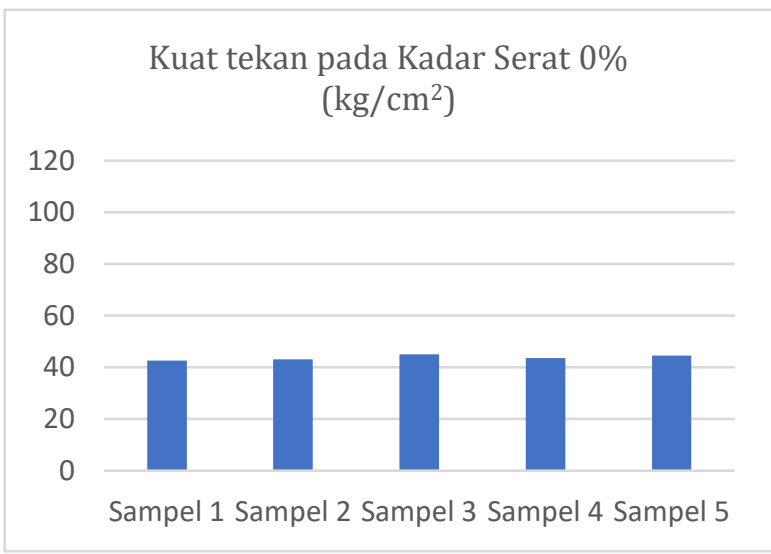

Gambar 2. Pengujian kuat tekan paving block dengan campuran HDPE dan serat bendrat 1\%

Nilai terkecil yang dihasilkan sebesar $42,63 \mathrm{~kg} / \mathrm{cm}^{2}$ dan nilai tertinggi ialah 45,11 $\mathrm{kg} / \mathrm{cm}^{2}$. Grafik hasil uji kuat tekan paving block tanpa serat bendrat dapat dilihat pada Gambar 2.

\section{Kuat Tekan Paving Block Kadar Serat}

\section{Bendrat 1\%}

Hasil uji kuat tekan sampel dengan penambahan serat bendrat $1 \%$ bisa dilihat pada Tabel 3. Nilai kuat tekan tertinggi yang dihasilkan oleh uji serat bendrat $1 \%$ ialah $63,46 \mathrm{~kg} / \mathrm{cm}^{2}$. Nilai kuat tekan terendah yang didapat yaitu hanya sebesar $58,23 \mathrm{~kg} / \mathrm{cm}^{2}$.

Tabel 3. Hasil Uji Kuat Tekan Paving Blok Berbahan Dasar Limbah Plastik Hdpe Dengan Kadar Serat 1\%

\begin{tabular}{|c|c|c|}
\hline No & Kadar Serat 1\% & Kuat Tekan (kg/cm2) \\
\hline 1 & Sampel 1 & 62,45 \\
\hline 2 & Sampel 2 & 60,23 \\
\hline 3 & Sampel 3 & 58,61 \\
\hline 4 & Sampel 4 & 58,23 \\
\hline 5 & Sampel 5 & 63,46 \\
\hline
\end{tabular}

Sumber: Analisa

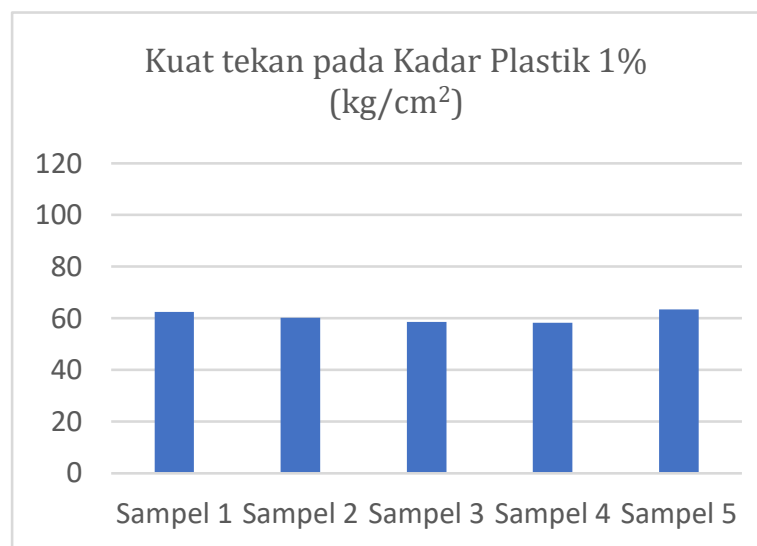

Gambar 3. Pengujian kuat tekan paving block dengan campuran HDPE dan serat bendrat $1 \%$

Nilai ini tidak memenuhi standar mutu yang diatur dalam SNI. Grafik 
Hutauruk, D.M.H. (2021). Pengaruh Serat Bendrat Terhadap Kuat Tekan Paving Block Berbahan Dasar Limbah Plastik HDPE

perbandingan hasil uji kuat tekan paving block dengan kadar serat $1 \%$ dapat dilihat pada Gambar 3.

\section{Kuat Tekan Paving Block Kadar Serat Bendrat 2\%}

Pada pengujian kuat tekan dengan variasi kadar serat bendrat $2 \%$, terjadi peningkatan, dimana kuat tekan terendah sebesar 75,90 kg/ $\mathrm{cm}^{2}$ dan nilai kuat tekan tertinggi sebesar $85,7 \mathrm{~kg} / \mathrm{cm}^{2}$. Namun, kuat tekan yang dicapai masih belum sesuai dengan standar SNI.

Hasil pengujian dengan kadar serat bendrat $2 \%$ dapat dilihat pada Tabel 4 . Grafik perbandingan hasil uji kuat tekan paving block dengan kadar serat $2 \%$ dapat dilihat pada Gambar 4.

Tabel 4. Hasil Uji Kuat Tekan Paving Blok Berbahan Dasar Limbah Plastik Hdpe Dengan Kadar Serat 2\%

\begin{tabular}{|c|c|c|}
\hline No & Kadar Serat 2\% & Kuat Tekan $\left(\mathrm{kg} / \mathrm{cm}^{2}\right)$ \\
\hline 1 & Sampel 1 & 82,1 \\
\hline 2 & Sampel 2 & 79,8 \\
\hline 3 & Sampel 3 & 80,41 \\
\hline 4 & Sampel 4 & 75,9 \\
\hline 5 & Sampel 5 & 85,7 \\
\hline
\end{tabular}

Sumber: Analisa

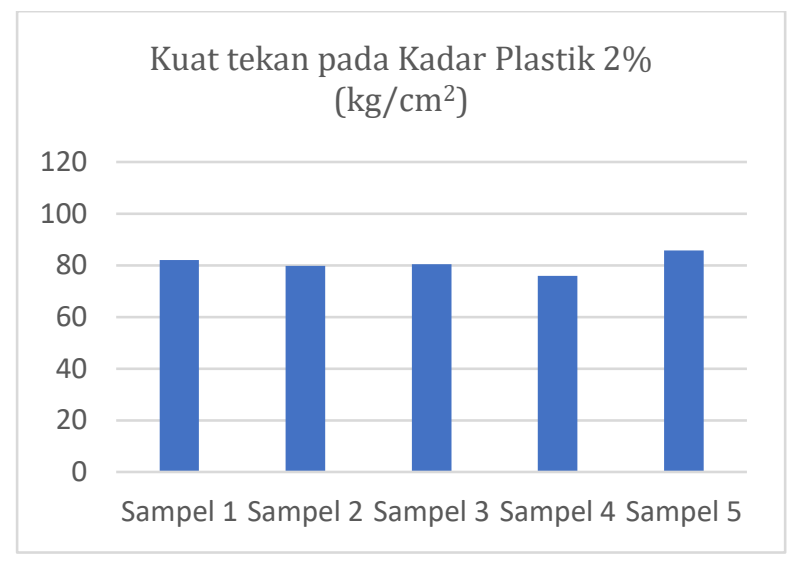

Gambar 4. Pengujian Kuat Tekan Paving Block Dengan Campuran Hdpe Dan Serat Bendrat 2\%

\section{Kuat Tekan Paving Block Kadar Serat}

\section{Bendrat 3\%}

Hasil pengujian kuat tekan paving block dengan kadar serat bendrat 3\% dimuat dalam Tabel 5. Terlihat nilai kuat tekan tertinggi sebesar $110,7 \mathrm{~kg} / \mathrm{cm}^{2}$ dan kuat tekan terendah sebesar $98,8 \mathrm{~kg} / \mathrm{cm}^{2}$. Grafik kuat tekan paving block dengan kadar serat bendrat 3\% juga dapat dilihat pada Gambar 5.

Tabel 5. Hasil Uji Kuat Tekan Paving Blok Berbahan Dasar Limbah Plastik Hdpe Dengan Kadar Serat 3\%

\begin{tabular}{|c|c|c|}
\hline No & Kadar Serat 3\% & Kuat Tekan $\left(\mathrm{kg} / \mathrm{cm}^{2}\right)$ \\
\hline 1 & Sampel 1 & 106,6 \\
\hline 2 & Sampel 2 & 110,3 \\
\hline 3 & Sampel 3 & 98,8 \\
\hline 4 & Sampel 4 & 100,9 \\
\hline 5 & Sampel 5 & 110,7 \\
\hline
\end{tabular}

Sumber: Analisa 


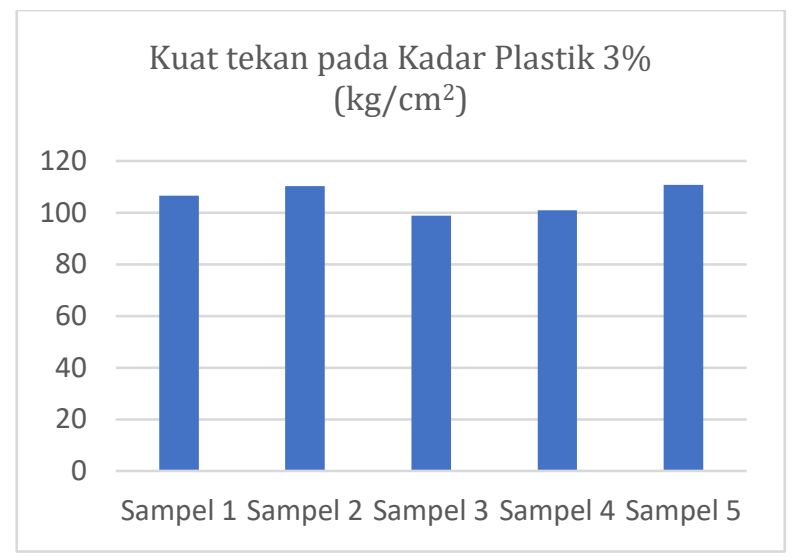

Gambar 5. Pengujian Kuat Tekan Paving Block

Dengan Campuran Hdpe Dan Serat Bendrat 3\%

\section{Kuat Tekan Paving Block Kadar Serat Bendrat dan Standar SNI}

Kuat tekan paving block yang dihasilkan dari serat bendrat dengan kadar 3\% sudah memenuhi standar kuat tekan SNI, yaitu paving block mutu D (102 $\mathrm{kg} / \mathrm{cm}^{2}$ ). Grafik nilai rata-rata kuat tekan paving block dengan variasi kadar serat dan perbandingannya dengan standar SNI dapat dilihat pada Gambar 5.

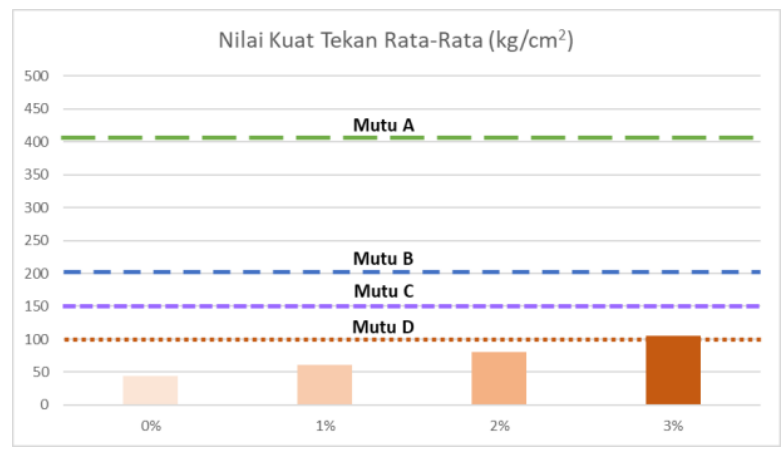

Gambar 6. Perbandingan Kuat Tekan Paving Block Berbahan Dasar Hdpe Dengan Variasi Serat Bendrat

\section{KESIMPULAN}

Dari hasil dan pembahasan yang telah diuraikan, dapat diambil kesimpulan bahwa penggunaan serat bendrat sebagai campuran paving block berbahan dasar plastik dapat meningkatkan nilai kuat tekannya. Dengan kadar serat bendrat 3\%, paving block yang dihasilkan dapat digunakan sebagai perkerasan yang tidak menerima beban besar, misalnya perkerasan taman, atau halaman rumah. Kuat tekan yang dihasilkan mencapai $110,7 \mathrm{~kg} / \mathrm{cm}^{2}$.

\section{DAFTAR PUSTAKA}

Adibroto F. (2014). Pengaruh Penambahan Berbagai Jenis Serat pada Kuat Tekan Paving Block. Jurnal Rekayasa Sipil. Volume 10 No. 1.

Dwiyono. (2000). Perbedaan Mutu Genteng Beton yang Dihasilkan Dengan Penambahan Serat Sabut Kelapa dan Pengurangan Pasir Sesuai Prosentase Serat yang Ditambahkan, Skripsi. Jurusan Pendidikan Teknik Bangunan, Fakultas Teknik, Universitas Negeri Yogyakarta (UNY).

Enda D., Sastra M., dkk. (2019). Penggunaan Plastik Tipe PET Sebagai Pengganti Semen Pada Pembuatan Paving Block. Jurnal Inovtek Polbeng. Volume 9 No.2.

Gusniar I.N. (2018). Metode Pembuatan Paving Block Segi Enam Berbahan Sampah Plastik dengan Mesin Injection Molding. Barometer. Volume 3 No. 2.

Adminkanal. 2015. Rangkaian HLH 2015-Dialog Penanganan Sampah Plastik. Diunduh di http://kanalkomunikasi.pskl.menlhk.go.id/ra ngkaian-hlh-2015-dialog-penanganansampah-plastik/

Kartika I.S. \& Ahmad B.M. (2019). Pemanfaatan Limbah Plastik HDPE (High Density Polythylene) Sebagai bahan pembuatan paving block. Bulletin utama Teknik. Volume 15 No. 1.

Purwaningrum, Pramiati. 2016. Upaya Mengurangi Timbulan Sampah Plastik di Lingkungan. Universitas Trisakti. Jakarta.

SNI-03-0691-1996, Persyaratan Mutu Bata Beton (Paving Block). 
Hutauruk, D.M.H. (2021). Pengaruh Serat Bendrat Terhadap Kuat Tekan Paving Block Berbahan Dasar Limbah Plastik HDPE

Ubaidillah Z., dkk. (2018). Pemanfaatan Sampah Plastik dan Organik dalam Pembuatan Paving Block Menggunakan Mesin Press. AlArd: Jurnal Teknik Lingkungan. Volume 4 No. 1. 